\title{
How does completing an Ironman triathlon affect postural control?
}

\section{Como a conclusão de um triatlo Ironman afeta o controle postural?}

\author{
Hugo Eduardo de Amorim \\ (D) https://orcid.org/0000-0002-8847-4491 \\ Gilmar Moraes Santos ${ }^{1}$ \\ (D) https://orcid.org/0000-0002-6322-9238 \\ Luis Mochizuki² \\ (D) https://orcid.org/0000-0002-7550-2537 \\ Evangelos Pappas ${ }^{3}$ \\ (D) https://orcid.org/0000-0002-8340-0303 \\ Vanessa Lima Silva ${ }^{1}$ \\ (1D) https://orcid.org/0000-0002-9640-782X \\ Patrícia Parizotto ${ }^{\top}$ \\ (D) https://orcid.org/0000-0003-1634-1822 \\ Carolina Buzzi da Silveira \\ (D) https://orcid.org/0000-0001-6915-1155
}

Abstract-Despite the increase in the number of Ironman competitions worldwide, thousands of athletes have been joining Ironman experience but only a few studies have been published on the effects of this competition on postural control. This study aims to investigate the ability to maintain a static posture in three different positions before and after an Ironman competition and the blood glucose level behavior. Forty-nine volunteers underwent balance evaluation using the force plate VSR ${ }^{\mathrm{TM}}$ Sport. The area of the center of gravity (ACOG) was assessed pre- and post-competition in the bipodal, unipodal, and tandem postures. Glucose levels were also assessed concurrently. The ACOG findings showed a significant post-competition increase in the three postures assessed, with no significant interaction between the postures. The glucose test showed an increase in the post-competition glycemic levels. The findings showed reduced postural control, suggesting that prolonged exercise stimulation could lead to a disturbance in postural control.

Key words: Athletes; Blood Glucose; Postural Control.

Resumo - Apesar do aumento no número de competiçóes Ironman em todo o mundo e milhares de atletas se juntarem à experiência Ironman, apenas alguns estudos foram publicados sobre os efeitos dessa competição no controle postural. Este estudo tem como objetivo investigar a capacidade de manter uma postura estática em três posiçôes diferentes antes e depois de uma competição de Ironman e o comportamento do nivel de glicose no sangue. Quarenta e nove voluntários foram submetidos à avaliação do equilibrio usando uma plataforma de força, VSRTM Sport. A área do centro de gravidade (ACOG) foi avaliada prée pós-competição nas posturas bipodal, unipodal e tandem. Os niveis de glicose também foram avaliados simultaneamente. Os achados do ACOG mostraram um aumento significativo pós-competição nas três posturas avaliadas, sem interação significativa entre as posturas. O teste de glicose mostrou aumento nos niveis glicêmicos pós-competiçâo. Os resultados mostraram decréscimo no controle postural, sugerindo que a estimulação prolongada ao exercício poderia levar a um distúrbio no controle postural.

Palavras-chave: Atletas; Controle Postural; Glicemia.
1 State University of Santa Catarina. Florianópolis, SC. Brazil.

2 São Paulo University. São Paulo, SP. Brazil.

3 The University of Sydney. Sydney. Austrália.

Received: December 03, 2019 Accepted: May 15, 2020

How to cite this article de Amorim HE, Santos GM, Mochizuki L, Pappas E, Silva VL, Parizotto P, Silveira CB. How does completing an Ironman triathlon affect postural control? Rev Bras Cineantropom Desempenho Hum 2020, 22:e70430. DOl: http://dx.doi. org/10.1590/1980-0037.2020v22e70430

Copyright: This work is licensed under a Creative Commons Attribution 4.0 International License. 


\section{INTRODUCTION}

The triathlon is a three-stage sport that commenced in the 1970s and involves swimming, cycling, and running. "Ironman" is the name of the most famous triathlon circuit worldwide, consisting of $3.8 \mathrm{~km}$ of swimming, $180 \mathrm{~km}$ of cycling, and $42 \mathrm{~km}$ of running. Such open-air distances are completed within a mean time of 12.5 hours $^{1}$.

During the triathlon, up to $37.7 \%$ of athletes get injured; of these, $38.2 \%$ experience serious injuries ${ }^{2}$. The lower limbs have the highest injury rates and their potential for injury increases with time while the number of injuries peaks among athletes who complete the distance with more than 14 hours to ${ }^{3}$.

Studies have shown that postural control decreases after high-level exercise among healthy individuals, regardless of whether the physical activity is global such as running or isolated such as isokinetic ${ }^{4,5}$.

A study on static postural control involving endurance athletes and healthy subjects showed decreased postural control measured with a plate force after strenuous physical exercise. Both groups showed an increase in the total body sway path ${ }^{6}$.

The Ironman distance triathlon is an ultra-endurance activity that causes significant changes in several physiological parameters. Accordingly, chemical markers, such as glucose and lactate levels, have long been used as fatigue or chronic fatigue indicators. Circulating glucose depletion and increased lactate levels are common during fatigue, as well as extreme tiredness and loss of motor skills in performing the sporting gesture ${ }^{7,8}$.

Studies have investigated the changes in the relationship between central and peripheral motor control after the aerobic threshold was attained, causing alterations in motor control ${ }^{9}$. A study noted that after increasing intense physical exercises, amateur runners experienced fatigue and showed reduced ability to stabilize the trunk, limiting their performance ${ }^{10}$. Indeed, the few experiments in which fatigue was induced in triathletes studied cardiovascular and endocrine changes, and energy aspects, but had no successes to examine postural control before and after a triathlon event ${ }^{11-14}$. Furthermore, these controlled studies were conducted in indoor environments, in laboratories, using a stationary bicycle, and not in competitions where changes in temperature, humidity, elevation, and emotional factors may affect athletic performance.

Thus, endurance sports, presumably, could affect the mechanism of sensorimotor control of balance; thereby, increasing the risk of injury among athletes participating in long-distance events. There is currently limited literature on effects of triathlon competition on postural control. Identifying and measuring the differences of postural-control behaviour pre- and post-competition using stability testes from the plate force could

Thus, the objective of this study was to assess the ability to maintain a static posture among athletes competing in long-distance events and glucose levels. 


\section{METHODS}

\section{Participants}

Participants who enrolled in the Ironman distance triathlon events held in the cities of Florianópolis (2015-2016) and Fortaleza (2015) were eligible for study inclusion. The average of each event is 1.600 athletes, almost all amateur category. We access the most part of the athletes, however, less than $10 \%$ wished to be included for the study. Along with of the data collections many participants were excluded from the study for different reasons, the most relevant are, did not have the physical condition to complete the study task or gap between finish and last collection more than 20 minutes.

This study was completed with 49 male volunteers, $74 \%$ presented right side dominant limb and 16\% left side, who successfully completed the event within less than 17-hours, time limit stipulated by race rules, and who were enrolled in the amateur category was non-probabilistically and intentionally selected. The following exclusion criteria were used: (1) need for medical intervention in the post-event period and (2) time between completing the event and post-event test longer than 20 minutes.

Participants were informed about the study by e-mail or through the organizers of the sporting events, sports advisory services, clubs, and sports federations. The study was also presented at the technical congress two days before the Ironman event. Participants were informed about the purpose of the study in order to collect pre- and post-competition information regarding the maintenance of static posture and blood glucose levels. All participants signed an informed consent form. The study was approved by the Human Research Ethics Committee (opinion number 1.087.547).

\section{Procedures}

Data were collected onsite at the venue of the sports activities because of the need to collect the data as close as possible to the end of the physical activity. The selected volunteers were followed for two days by the same rater.

The first data collection was performed as close to the beginning of the triathlon and the second occurred immediately after the athletes completed the triathlon (3.8 km of swimming, $180 \mathrm{~km}$ of cycling, and $42.2 \mathrm{~km}$ of running). Demographic data, including age, height, weight, and dominant limb (limb used to kick a ball), and the time used to complete the competition were collected from all participants (Table 1).

The stipulated evaluation sequence was (1) glycemic levels and (2) maintenance of static posture.

To determinate the blood glucose level from each athletes was used a validity portable device, the Accutrend Plus system ${ }^{15}$. The system is a handheld electronic device consisting of a glucose monitor which displays the numerical value of the blood glucose concentration of an individual expressed as milligrams per deciliter $(\mathrm{mg} / \mathrm{dl})$ using a small sample of blood tissue. Initially, the hands of the volunteer were sanitized using 70\% ethanol and then a finger was pricked to draw blood. This blood drop was 
applied to the test strip of the device to determine the blood glucose and lactate concentrations ${ }^{16}$. The lancets and test strips used for the individual measurements were discarded in a suitable place (container for puncturing materials and biological waste).

The VSR ${ }^{\mathrm{TM}}$ Sport force plate and the NeuroCom ${ }^{\circledR}$ Balance Manager software (Neurocom International, Inc, Clackamas, OR; a computerized assessment and management tool for balance and mobility disorders) were used to assess static posture (Balance and mobility academy 2018). The NeuroCom ${ }^{\circledR}$ Balance Manager software program measures postural control as a function of the postural sway velocity and area, recorded in degrees per second ${ }^{17}$. According to the interpretation suggested by NeuroCom, a higher scores represent worse balance ${ }^{6,9}$. Two data collections were performed using the VSR Sport force plate during the events. Data were collected according to the Stability Evaluation Test (SET) protocol. This protocol assesses individuals at three different positions (bipodal, unipodal, and tandem). In the bipodal position, the athletes placed their feet together, parallel, and their hands on their hips and faced forwards. In the unipodal position, the athletes stood only on the dominant lower limb, maintaining the contralateral limb in a suspended position by slightly flexing the hip and flexing the knee, with the hands on the hips. In the tandem position, the athletes were asked to stand on both feet, aligned, with the dominant limb behind and the hands on the hips. In each position, the athlete remained standing still for 20 seconds.

The first data collection was performed as close as possible to the start of the competition within the last 48 hours before the competition. The second data collection was performed shortly after the end of the Ironman competition, up to 20 minutes after completion, using the same protocol as in the first data collection.

During the collections, the volunteer remained standing on the base of the plate, facing forwards, and barefoot to prevent the effect of shoes on balance. During the test, only the rater and a member of the data collection team who helped the athlete in case of loss of balance were allowed to be present. They were both close to the athlete but did not interfere with the test.

\section{Data analysis}

Numerical data from each motor control test in the positions described above were collected from the force plate and stored for further evaluation.

A database was organized into spreadsheets for each variable. The data were exported to the Microsoft Excel program to prepare tables and graphs.

The primary outcome variable was the maintenance of static posture in the pre- and post-triathlon tests. This variable was assessed in the Neurocom VSR ${ }^{\mathrm{TM}}$ Sport force plate. The secondary outcome variable was the pre- and post-competition blood glucose level.

Data from the balance tests collected using VSR ${ }^{\mathrm{TM}}$ Sport were managed and processed using the software of the device at a frequency of $100 \mathrm{~Hz}$, si- 
multaneously with each test, and stored in the computer for analysis. A routine was prepared in MatLab ${ }^{\circledR}$ to collect data on the area of the center of gravity (ACOG) variable in the three postures used: bipodal, unipodal, and tandem.

The levels of the blood marker (glucose) were assessed using the device within 60 seconds from the collection. As soon as the device produced the result, the researcher manually recorded the value in a previously prepared worksheet.

\section{Statistical analysis}

Descriptive statistics with means, standard deviation, and 95\% confidence interval were used to characterize the variables. Data normality was assessed using the Shapiro-Wilk test. The data were tabulated in the Statistical Package for the Social Sciences (SPSS for Windows v.20.0 - licensed for use by the Santa Catarina State University [Universidade do Estado de Santa Catarina - UDESC]).

Factorial repeated-measures analysis of variance (ANOVA) with Bonferroni adjustment was used to assess the effect of time (pre and post) and of different postures (bipodal, unipodal, and tandem) on static posture (ACOG).

For both pre- and post-event postural stability tests was used descriptive statistic (average and standard deviation) and the paired Student t-test to detect differences between the both events pre- and post-event. The significance level was at $\mathrm{p} \leq 0.05$.

\section{RESULTS}

The measurements of performance in maintaining static postural control using the SET protocol are outlined in Table 2 and describe ACOG before and after the triathlon and in the three postures. Furthermore, the composite measure, which is the mean of the three different postures in the pre- and post-competition phases, was also assessed. The findings of the ANOVA showed a significant effect on the ACOG variables (Table 2 and Figure 1).

Balance was significantly worse after the triathlon in all three postures. Regarding the comparison between postures, the post hoc analysis showed no significant differences in ACOG between the three postures, although the unipodal and tandem postures had more similar ACOG values compared to the bipodal posture.

Glucose values were higher $(\mathrm{p}=0.001)$ in the post-competition test than in the pre-competition test. The results showed a mean increase in glucose levels of $10.5 \mathrm{mg} / \mathrm{dl}$ (Table 3).

Table 1. Participants' characteristics.

\begin{tabular}{lcccc}
\hline \multirow{2}{*}{ n) } & Age (years) & Height (cm) & Weight $(\mathrm{kg})$ & Race time (min) \\
\cline { 2 - 5 } & $\mathrm{M}($ S.D.) & M (S.D.) & M (S.D.) & M (S.D.) \\
\hline 49 & $38.3(8.1)$ & $174(6.1)$ & $75(5.0)$ & $738.5(93)$ \\
\hline
\end{tabular}

Note. M: Mean; S.D.: standard deviation. 
Table 2. Mean and standard deviation of the pre- and post-competition ACOG behavior in three different postures $(n=49)$

\begin{tabular}{|c|c|c|c|c|c|c|c|c|}
\hline \multirow{3}{*}{ Variable } & \multirow{3}{*}{ Phase } & \multicolumn{7}{|c|}{ Posture } \\
\hline & & $\mathrm{BP}$ & $95 \% \mathrm{Cl}$ & UP & $95 \% \mathrm{Cl}$ & TP & $95 \% \mathrm{Cl}$ & $\mathrm{CP}$ \\
\hline & & M (S.D.) & & M (S.D.) & & M (S.D.) & & M (S.D.) \\
\hline \multirow[t]{2}{*}{$\mathrm{ACOG}(\mathrm{m})$} & Pre & $0.078(0.12)$ & $0.074-0.231$ & $0.137(0.27)$ & $0.015-0.290$ & $0.129(0.28)$ & $0.024-0.282$ & $0.115(0.23)$ \\
\hline & Post & $0.191(0.26)$ & $0.038-0.374$ & $0.400(0.87)$ & $0.248-0.553$ & $0.461(0.87)$ & $0.308-0.614$ & $0.351(0.73)$ \\
\hline
\end{tabular}

Note. M: Mean; S.D.: standard deviation; Groups and conditions were compared by analysis of variance with Bonferroni correction. Area of the Center Of Gravitiy (ACOG); Confidence Interval (95\% Cl); Bipodal posture (BP); Unipodal posture (UP); Tandem posture (TP); Composite postures (CP).

Table 3. Representation of the pre- and post-competition mean and standard deviation values from the blood glucose.

\begin{tabular}{lllll}
\hline & (n) & Pre- competition & Post- competition & P \\
\cline { 3 - 5 } & & M (S.D.) & M (S.D.) & \\
\hline Blood Glucose $(\mathrm{mg} / \mathrm{dl})$ & 49 & $99.5(15)$ & $110(32)$ & 0.001 \\
\hline
\end{tabular}

Note. M: Mean; S.D.: standard deviation.

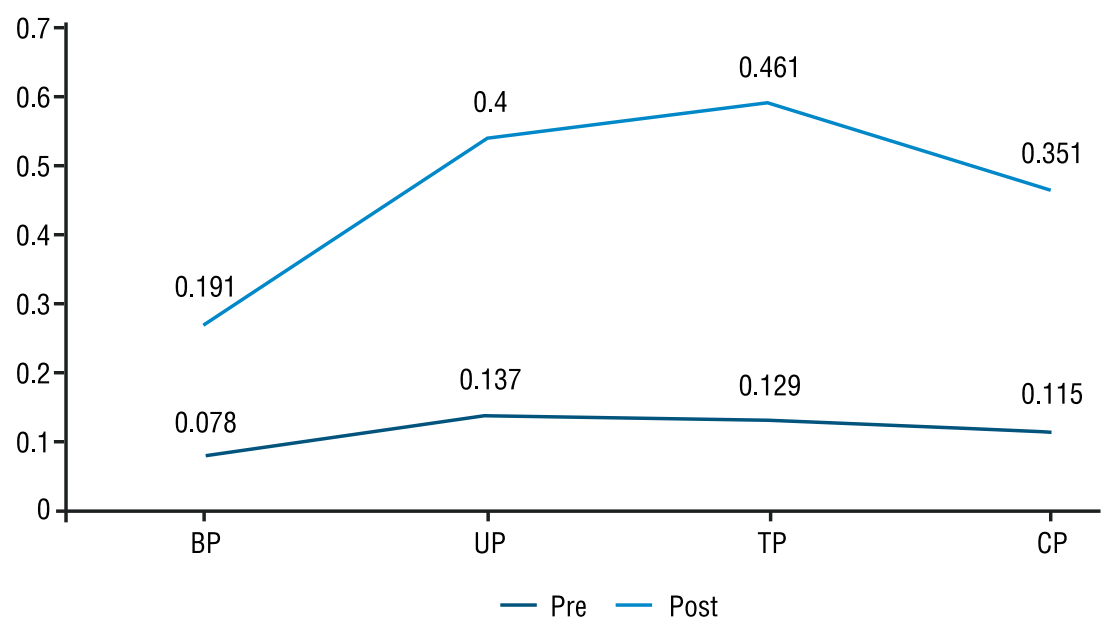

Figure 1. Estimated Marginal Means of the area of the Center Of Gravity

Note. Groups and conditions were compared by analysis of variance with Bonferroni correction. Bipodal posture (BP); Unipodal posture (UP); Tandem posture (TP); Composite postures (CP).

\section{DISCUSSION}

This study aimed to examine the effect of completing an Ironman on static postural control and glucose levels. To our knowledge, this is the first study investigating changes in postural control after prolonged physical activity before and after an Ironman competition. There were two main findings: compared to baseline values, postural control was worse and glucose levels were elevated after the completion of the Ironman.

The main findings of the present study showed the overall effect of the Ironman-distance triathlon caused a significant increase in ACOG, indicating decreased motor control in maintaining static posture. Furthermore, the findings confirmed our hypothesis that postural control decreases but refuted our hypothesis that glucose levels will go down.

Decreased postural control was shown by the increased ACOG in the three different postures tested in the post-competition phase, high- 
lighting a higher difficulty in maintaining static posture compared to the pre-competition phase and confirming our hypothesis on postural control.

Several variables may be involved in the degradation of postural control. Fatigue may be the plausible and most comprehensive explanation for the degradation observed in this study. Fatigue has several triggers such as dehydration, blood lactate levels, psychological status, including sadness, and excessive neural activity, which reduces the stock of neurotransmitters, among others. A study reported that young and healthy individuals show difficulties walking after a quadriceps muscle fatigue protocol with shortened sliding reaction times on smooth surfaces and increased potential for falling ${ }^{18}$. As showed in the study, balance decreases among athletes in with increased fatigue-inducing exercises ${ }^{19}$. Segmental and global exercise stress tests apparently also progress to loss of motor control in maintaining posture ${ }^{4,5}$. Studies relate changes in muscle control to changes in aerobic threshold after an increase in prolonged physical activity ${ }^{8}$.

Similar to the findings in the present study, ultra-marathon mountain runners showed decreased static postural control after a mean of the 15 hours and 56 minutes running ${ }^{20}$. The participants of this study showed a mean completion time of 738 minutes, (just over 12 hours and eighteen minutes), and presented similar postural control results of the previews studies that evaluate runners, indicating possible changes in aerobic threshold due to the time of exposure to physical exercise independent of the sport activity.

However, identifying a single cause is currently unfeasible, given the limited number of clinical and psychological data collected in this study.

Regarding the decrease in blood glucose levels, our hypothesis was not confirmed because the participants showed higher blood glucose levels after the Ironman competition than before the competition. During training sessions in the preparation period for a competition, only $66 \%$ of Ironman amateur athletes achieve the recommended intake of carbohydrates; a glucose source, and this poor intake may trigger low blood glucose levels. During the competition, it is possible that because of the large supply of food throughout the race course provided by the event organizer, such as bananas, oranges, cakes, soft drinks, sports drinks, soup, etc., in addition to individual nutrition, athletes naturally have different sources of carbohydrates and achieve satisfactory glucose intake during the competition; thus, enabling the maintenance of blood glucose levels ${ }^{21,22}$.

Although glucose is a key source of energy for long-distance events, several mechanisms are involved in maintaining its blood levels ${ }^{23}$. Recently published studies reported no depletions of glycemic levels among ultra-endurance athletes, particularly among Ironman athletes, even when assessing elite athletes ${ }^{24}$. A study following a triathlete for 33 Ironman competitions over 33 consecutive days showed no significant changes in blood plasma, including blood glucose levels, despite the loss of body mass ${ }^{25}$. Therefore, our results of glycemic levels corroborate recently published findings, although they fail to support the hypothesis of an expected decrease in the initial pre-competition value. 
The research limitations were the difficulty of convincing athletes to participate in all collections during the Ironman event, sample loss due to withdrawal during the competition, the poor general condition of athletes at the end of the race, the requirement for medical intervention, and the inability to perform some tests determined the final number of volunteers. Regarding the balance data collection, noise pollution could not be controlled because the data collection site was close to the finish line where the supporters were located. Regarding the glucose test, the type and quantity of food intake or medicine administered during the event could not be controlled. Finally, as we only measured post Ironman variables immediately after the competition we are unable to ascertain when balance glucose return to baseline levels.

\section{CONCLUSION}

The results from this study showed that amateur Ironman athletes had decreased post-competition static postural control. Furthermore, the results also showed an increase in the post-competition glycemic levels of the athletes; thus, suggesting that the food intake during the competition efficiently maintained the glycemic levels.

\section{Acknowledgements}

After ultra-endurance sports, athletes who completed an event (e.g. Ironman) it may be beneficial to avoid activities that may challenge their balance to avoid falls and injuries. Future research should investigate the time that it takes for balance to return to baseline values.

\section{COMPLIANCE WITH ETHICAL STANDARDS}

\section{Funding}

This research received grant from Santa Catarina Research Foundation FAPESC (2019TR602; 2017TR764) and Coordination for higher Education Staff Development - CAPES.

\section{Ethical approval}

Ethical approval was obtained from the local Human Research Ethics Committee-CEP/UDESC and the protocol (no. 1,087,547) was written in accordance with the standards set by the Declaration of Helsinki.

\section{Conflict of interest statement}

The authors have no conflict of interests to declare.

\section{Author Contributions}

Conceived and designed the experiments: HEA, GMS. Performed the experiments: PP, VLS, CBS. Analyzed the data: GMS, LM. Contributed reagents/materials/analysis tools: EP. Wrote the paper: HEA. 


\section{REFERENCE}

1. Ironman. The IRONMAN Story. 2015; Available from: http://www.ironman. com/triathlon/history.aspx\#axzz3pgpC4mgX [2015 Oct 11].

2. Rimmer $\mathrm{T}$, Coniglione $\mathrm{T}$. A temporal model for nonelite triathlon race injuries. Clin J Sport Med 2012;22(3):249-53.

3. Gosling C, Forbes A, Gabbe B. Identification of crash and fall risks during the cycling mount and dismount actions in triathlon competitions: a video analysis. Inj Prev 2012;18(Suppl 1):A58-A.

4. Barati A, Safarcherati A, Aghayari A, Azizi F, Abbasi H. Evaluation of relationship between trunk muscle endurance and static balance in male students. Asian J Sports Med 2013;4(4):289.

5. Frank BS, Gilsdorf CM, Goerger BM, Prentice WE, Padua DA. Neuromuscular fatigue alters postural control and sagittal plane hip biomechanics in active females with anterior cruciate ligament reconstruction. Sports health 2014;6(4):301-8.

6. Nagy E, Toth K, Janositz G, Kovacs G, Feher-Kiss A, Angyan L, et al. Postural control in athletes participating in an ironman triathlon. Eur J Appl Physiol 2004;92(4-5):407-13.

7. Wilmore JH CD, Kenney WL. Fisiologia do esporte e do exercício. 5 ed. Sao Paulo: Manuele Barueri; 2013. p. 50-64.

8. Mcardle WD KF, Katch V. Fisiologio do exercício. 7 ed. Rio de Janeiro: Gambara Koogan; 2011.

9. Tong TK, Wu S, Nie J, Baker JS, Lin H. The occurrence of core muscle fatigue during high-intensity running exercise and its limitation to performance: the role of respiratory work. J Sports Sci Med 2014;13(2):244.

10. Kovacs EJ, Birmingham TB, Forwell L, Litchfield RB. Effect of training on postural control in figure skaters: a randomized controlled trial of neuromuscular versus basic off-ice training programs. Clin J Sport Med 2004;14(4):215-24.

11. Rifai N, Douglas P, O'toole M, Rimm E, Ginsburg G. Cardiac troponin T and I, echocardiographic [correction of electrocardiographic] wall motion analyses, and ejection fractions in athletes participating in the Hawaii Ironman Triathlon. Am J Cardiol 1999;83(7):1085-9.

12. Whyte G, Lumley S, George K, Gates P. Physiological profile and predictors of cycling performance in ultra-endurance triathletes. J Sports Med Phys Fitness 2000;40(2):103.

13. Ginsburg GS, O’Toole M, Rimm E, Douglas PS, Rifai N. Gender differences in exercise-induced changes in sex hormone levels and lipid peroxidation in athletes participating in the Hawaii Ironman triathlon: Ginsburg-gender and exerciseinduced lipid peroxidation. Clin Chim Acta 2001;305(1-2):131-9.

14. Laursen PB, Rhodes EC, Langill RH, McKenzie DC, Taunton JE. Relationship of exercise test variables to cycling performance in an Ironman triathlon. Eur J Appl Physiol 2002;87(4-5):433-40.

15. Coqueiro RS, Santos MC, Neto JdSL, Queiroz BMd, Brügger NAJ, Barbosa AR. Validity of a portable glucose, total cholesterol, and triglycerides multi-analyzer in adults. Biol Res Nurs 2014;16(3):288-94.

16. Accutrend. Manual Accutrend ${ }^{\circledR}$ Plus system. Roche; Available from: http://www. roche.com/products/product-details.htm?type=product\&id=247 [2015 Nov 15].

17. Neurocom ${ }^{\circledR}$. Manual Stability Evaluation Test Available from: http://balanceandmobility.com/products/neurocom-test-protocols/\#set [2015 Nov 15].

18. Parijat $\mathrm{P}$, Lockhart TE. Effects of lower extremity muscle fatigue on the outcomes of slip-induced falls. Ergonomics 2008;51(12):1873-84.

19. Pau M, Ibba G, Attene G. Fatigue-induced balance impairment in young soccer players. J Athl Train 2014;49(4):454-61.

20. Marcolin G, Grainer A, Reggiani C, Bisiacchi P, Cona G, Petrone N, et al. Static and Dynamic Postural Changes after a Mountain Ultra-Marathon of $80 \mathrm{~km}$ and 5500 D+. Plos One 2016;11(5):e0155085. 
21. Pfeiffer B, Stellingwerff T, Hodgson AB, Randell R, Pöttgen K, Res P, et al. Nutritional intake and gastrointestinal problems during competitive endurance events. Med Sci Sports Exerc 2012;44(2):344-51.

22. Masson G, Lamarche B. Many non-elite multisport endurance athletes do not meet sports nutrition recommendations for carbohydrates. Appl Physiol Nutr Metab 2016;41(7):728-34.

23. Newsholme E LT, Duester G. Corrida: ciência do treinamento e desempenho. Sao Paulo: Phorte; 2006.

24. Mujika I, da Silveira Pereira F, Nosaka K. Blood markers of recovery from Ironman distance races in an elite triathlete. J Sports Med Phys Fitness 2017;57(7-8):1057-61.

25. Knechtle B, Rüst CA, Rosemann T, Martin N. 33 Ironman triathlons in 33 days-a case study. Springerplus 2014;3(1):269.

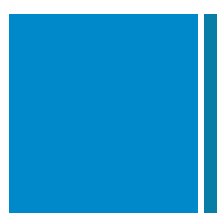

Corresponding author

Hugo Eduardo de Amorim

Centro de Ciências da Saúde e Esporte - CEFID

Rua Pascoal Simone, 358

Coqueiros - Florianópolis - SC, Brasil. CEP: 88080-350

E-mail:ft.hugo@gmail.com 